УДК 665.662.3

РАЗРАБОТКА ТЕХНОЛОГИЧЕСКОЙ СХЕМЫ ПОЛУЧЕНИЯ РАСТВОРИТЕЛЯ ДЛЯ УДАЛЕНИЯ

АСФАЛЬТОСМОЛОПАРАФИНОВЫХ ОТЛОЖЕНИЙ С ЦЕЛЬЮ ОБЕСПЕЧЕНИЯ ПОЖАРНОЙ И ПРОМЫШЛЕННОЙ БЕЗОПАСНОСТИ

\title{
DESIGN OF SOLVENT OBTAINING TECHNOLOGICAL SCHEME FOR REMOVING ASPHALT-RESIN-PARAFFIN DEPOSITS IN ORDER TO ENSURE FIRE AND INDUSTRIAL SAFETY
}

\author{
Э.Д. Муфтахова, Т.В. Васильева, О.А. Баулин, И.Ф. Хафизов, \\ Ф.Ш. Хафизов
}

Уфимский государственный нефтяной технический университет, г. Уфа, Российская Федерация

\author{
Elmira D. Muftakhova, Tatyana V. Vasilyeva, Oleg A. Baulin, \\ Ildar F. Khafizov, Fanil Sh. Khafizov \\ Ufa State Petroleum Technological University, \\ Ufa, Russian Federation \\ e-mail: il.elmira@mail.ru
}

Аннотация. Одним из опасных производственных объектов является нефтегазодобывающая скважина, которая требует большого внимания с точки зрения промышленной безопасности. На таких объектах необходимо осуществлять мероприятия по локализации и ликвидации последствий аварий. Нередко возникают аварии по причине накопления асфальтосмолопарафиновых отложений (АСПО). Поэтому для устранения нежелательных последствий следует обеспечивать эффективное удаление отложений или предотвращение их образования. 
Известен химический метод удаления отложений, основанный на применении органических растворителей. Такой способ борьбы с АСПО несложен в реализации, и при этом можно добиться высоких результатов. Авторами предлагается технологическая схема получения растворителя для реализации химического метода удаления отложений.

Целью работы является разработка технологической схемы получения растворителя на дожимной компрессорной станции добывающего завода для удаления АСПО со скважин. Задача заключается в получении эффективного растворителя с использованием добываемого газового конденсата.

Проведены лабораторные испытания по разработке растворителя с высокими показателями моющей, растворяющей и диспергирующей способностей. Результаты испытаний представлены в виде таблицы.

Разработана и описана технологическая схема для полученного экспериментальным путем эффективного растворителя для удаления АCПО.

Abstract. One of the dangerous production facilities is oil and gas producing well, which requires a lot of attention from the point of view of industrial safely. At such facilities, it is necessary to carry out measures to localize and eliminate the consequences of accidents. Often there are accidents due to the accumulation of asphalt-resin-paraffin deposits (ARPD). Therefore, to eliminate the undesirable consequences, it is necessary to ensure the effective removal of deposits or the prevention of their formation.

Known chemical method of removing deposits based on the use of organic solvents. This method of controlling ARPD is simple to implement, and wherein it is possible to achieve high results. Therefore, a technological scheme for obtaining a solvent for the implementation of a chemical method of removing deposits is proposed. Therefore, a solvent obtaining technological scheme for the implementation of a chemical method of removing deposits is proposed. 
The aim of the work is to develop a solvent obtaining technological scheme at the booster compressor station of the oil-gas-producing plant for removing ARPD from wells. The objectives consists in obtain an effective solvent with using produced gas condensate.

Laboratory tests to develop a solvent with high detergent, dissolving and dispersing abilities were carried out. The test results are presented in table form. The technological scheme for an experimentally obtained effective solvent for the removal of ARPD has been developed and described.

Ключевые слова: промышленная безопасность; скважины; асфальтосмолопарафиновые отложения; газовый конденсат; фракция стабильного газового конденсата; растворитель; технологическая схема

Key words: industrial safety; wells; asphalt-resin-paraffin deposits; gas condensate; fraction of stable gas condensate; solvent; technological scheme

Нефтегазовые скважины относятся к опасным производственным объектам (ОПО), к которым предъявляются требования промышленной безопасности в соответствии с Федеральным Законом № 116 [1]. При добыче нефти и газа могут возникнуть аварии и осложнения, которые могут привести к материальному и экологическому ущербу, а также к гибели людей.

В соответствии со статьей 9 Федерального Закона № 116 необходимо осуществлять мероприятия по локализации и ликвидации последствий аварий на опасном производственном объекте, а также принимать меры по устранению причин и профилактике подобных аварий [1]. Одним из распространенных источников аварий на нефтегазодобывающих скважинах является накопление асфальтосмолопарафиновых отложений (АСПО). Поэтому для обеспечения промышленной безопасности при добыче нефтепродуктов необходимо осуществлять мероприятия по предотвращению и удалению АСПО. 
Существует химический метод удаления отложений, который заключается в растворении АСПО с помощью различных органических составов. Такой метод хорош тем, что имеет высокую эффективность действия, которая сохраняется в течение длительного времени, и несложен в исполнении. Несмотря на это есть недостаток, который заключается в высокой стоимости эффективных реагентов для растворителя АСПО, а также в отсутствии универсального состава для отложений с разных типов месторождений. Поэтому подбор химических реагентов для растворения асфальтосмолопарафиновых отложений является сложным процессом, требующим множества лабораторных испытаний.

Нами были проделаны испытания в соответствии со стандартом [2]. В качестве объекта исследования выступила нефтегазоконденсатная скважина Оренбургского нефтегазоконденсатного месторождения (ОНГКМ), для которой разработали технологическую схему получения растворителя на основе добываемого газового конденсата.

На первом этапе лабораторных испытаний в качестве растворителя исследовался стабильный газовый конденсат с началом кипения $60{ }^{\circ} \mathrm{C}-$ «проба-1», который показал низкие моющую, растворяющую и диспергирующую способности, средние значения которых представлены в таблице 1.

Таблица 1. Эффективность растворителя «проба-1»

\begin{tabular}{|l|c|}
\hline \multicolumn{1}{|c|}{ Показатель } & Эффективность, \% \\
\hline Моющая способность & 1,5 \\
\hline Диспергирующая способность & 0,6 \\
\hline Растворяющая способность & 0,9 \\
\hline
\end{tabular}

На втором этапе лабораторных испытаний растворитель «проба-1» смешали с добавкой POX-1, зарекомендовавшей себя как высокоэффективное средство удаления АСПО в научных трудах [3-5]. Результаты полученного растворителя «проба-2» представлены в таблице 2. 
Таблица 2. Эффективность растворителя «проба-2»

\begin{tabular}{|l|c|}
\hline \multicolumn{1}{|c|}{ Показатель } & Эффективность, \% \\
\hline Моющая способность & 23,5 \\
\hline Диспергирующая способность & 6,1 \\
\hline Растворяющая способность & 17,7 \\
\hline
\end{tabular}

Из таблицы 2 видно, что «проба-2» имеет неплохие результаты эффективности растворения. В результате исследования было выявлено, что при использовании добавки POX-1 показатели эффективности увеличились в 10 и более раз.

Эффективность добавки проявляется за счет входящих в ее состав поверхностно-активного вещества (ПАВ) и полярного неэлектролита. Первый способен увеличивать эффект диспергирования отложений, повышать поверхностную активность растворителя, что способствует увеличению растворяющей способности. Полярный неэлектролит действует как сорастворитель, обеспечивая распределение и поддержание ПАВ в объеме состава растворителя АСПО. Роль ПАВ сводится к стабилизации агрегатов парафинов с адсорбированными ассоциатами асфальтенов [6].

Дальнейшие исследования заключались в изучении фракции стабильного газового конденсата (ст.г.к.) в качестве растворителя. Посредствам перегонки нестабильного газового конденсата ОНГКМ на отдельную фракцию ст.г.к. с началом кипения $170^{\circ} \mathrm{C}$ (н.к. $\left.170^{\circ} \mathrm{C}\right)$, получили растворитель «проба-3». Результаты исследований представлены в таблице 3.

Таблица 3. Эффективность растворителя «проба-3»

\begin{tabular}{|l|c|}
\hline \multicolumn{1}{|c|}{ Показатель } & Эффективность, \% \\
\hline Моющая способность & 20,6 \\
\hline Диспергирующая способность & 5,4 \\
\hline Растворяющая способность & 15,2 \\
\hline
\end{tabular}


Для увеличения показателей моющей и растворяющей способностей растворителя «проба-3» использовалась эффективная добавка к растворителю РОХ-1. Для полученного растворителя «проба-4» результаты средних значений представлены в таблице 4.

Таблица 4. Эффективность растворителя «проба-4»

\begin{tabular}{|l|c|}
\hline \multicolumn{1}{|c|}{ Показатель } & Эффективность, \% \\
\hline Моющая способность & 64,0 \\
\hline Диспергирующая способность & 27,9 \\
\hline Растворяющая способность & 36,1 \\
\hline
\end{tabular}

Из таблицы 4 видно, что добавка PОХ-1 повысила эффективность всех показателей исследуемого растворителя. В результате исследования было выявлено, что при использовании добавки POX-1 показатели эффективности увеличились в 2 и более раз.

Также в качестве растворителя «проба-5» изучалась фракция ст.г.к. с началом кипения $150{ }^{\circ} \mathrm{C}$ (н.к. $150{ }^{\circ} \mathrm{C}$ ). Результаты средних значений показателей эффективности растворителя представлены в таблице 5.

Таблица 5. Эффективность растворителя «проба-5»

\begin{tabular}{|l|c|}
\hline \multicolumn{1}{|c|}{ Показатель } & Эффективность, \% \\
\hline Моющая способность & 22,8 \\
\hline Диспергирующая способность & 6,0 \\
\hline Растворяющая способность & 16,8 \\
\hline
\end{tabular}

С целью повышения моющей, растворяющей и диспергирующей способностей растворитель «проба-5» смешали с добавкой POX-1, в результате был получен новый растворитель «проба-6». Средние значения показателей эффективности представлены в таблице 6.

Таблица 6. Эффективность растворителя «проба-6»

\begin{tabular}{|l|c|}
\hline \multicolumn{1}{|c|}{ Показатель } & Эффективность, \% \\
\hline Моющая способность & 67,4 \\
\hline Диспергирующая способность & 29,1 \\
\hline Растворяющая способность & 38,3 \\
\hline
\end{tabular}


Анализ результата испытаний растворителя на основе фракции ст.г.к. н.к. $150{ }^{\circ} \mathrm{C}$ и добавки POX-1 показал достаточно высокие показатели моющей и растворяющей способностей. Это означает, что его можно использовать в промышленности в качестве эффективного средства для удаления АСПО.

С целью оптимизации производственного процесса была разработана технологическая схема получения фракции ст.г.к. Н.к. $150{ }^{\circ} \mathrm{C}$ из нестабильного газового конденсата для использования на собственные нужды на ОНГКМ, принадлежащему ООО «Газпром добыча Оренбург» (рисунок 1).

Основной целью разработки технологической схемы являлась проверка надежности и эффективности работы разработанного растворителя «проба-6».

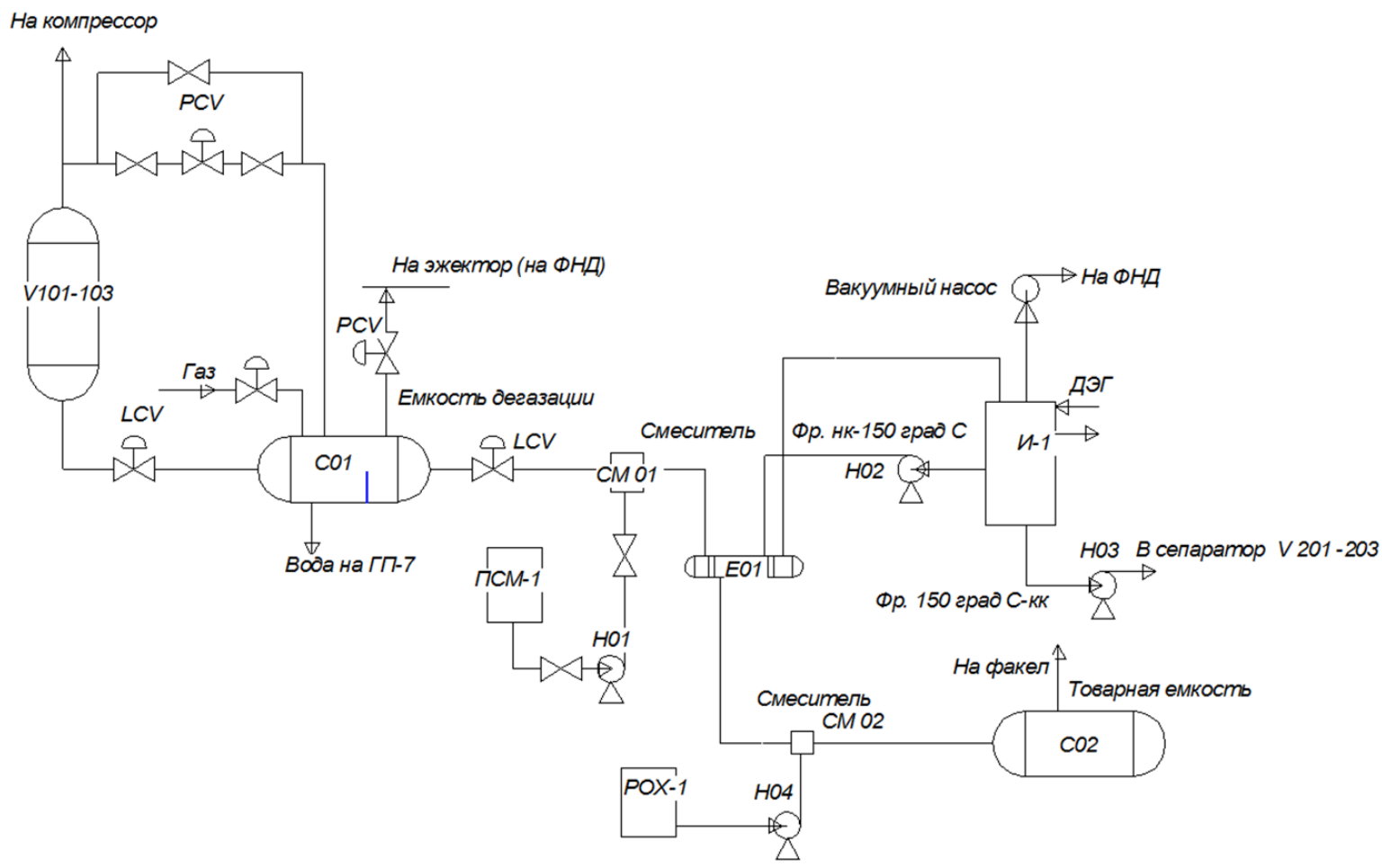

V-101-103 - сепаратор; C-01 - емкость дегазации; PCV, LCV - задвижки; CM-01, CM-02 - смеситель; H01, Н02, Н03, Н04 - насос; Е-01 - теплообменник; И-1 - испаритель; С-02 - товарная емкость; РОХ-1 - присадка

Рисунок 1. Технологическая схема для получения растворителя «проба-6» 
Исходное сырье (нестабильный газовый конденсат) подается в испаритель И-1, где с помощью 60 \%-го водного раствора диэтиленгликоля (ДЭГ) нагревается до температуры $80^{\circ} \mathrm{C}$. Вакуумный насос в испарителе И- 1 позволяет создать давление вакуума, за счет этого увеличивается температура нестабильного газового конденсата до $150{ }^{\circ} \mathrm{C}$.

В результате происходит выделение фракции ст.г.к. н.к. $150{ }^{\circ} \mathrm{C}$, которая с помощью насоса Н-02 подается в смеситель СМ-02, куда вторым потоком поступает добавка POX-1 с помощью дозирующего насоса Н-04. После смешения с добавкой РОХ-1 растворитель направляется в товарную емкость С-02. С низа испарителя И-1 с помощью насоса Н-03 вторым потоком выводится фракция ст.г.к. $150{ }^{\circ} \mathrm{C}-$ конец кипения, которая отводится в сепаратор V-201-203 на собственные нужды завода.

\section{Выводы}

Получен растворитель на основе фракции ст.г.к. н.к. $150{ }^{\circ} \mathrm{C}$ с добавкой POX-1, который показал высокие значения моющей $(67,4 \%)$ и растворяющей $(38,3$ \%) способностей, с возможностью использования его в промышленности в качестве эффективного средства для удаления АСПО.

Разработана технологическая схема, позволяющая стабилизировать нестабильный газовый конденсат и получать эффективное средство для удаления АСПО на добывающем заводе ООО «Газпром добыча Оренбург» с меньшими затратами и снижением воздействия на окружающую среду.

\section{Список используемых источников}

1. Федеральный закон от 21.07.1997 № 116-Ф3 «О промышленной безопасности опасных производственных объектов» (с посл. изм. и доп. от 29.07.2018 г.) // Информационно-правовое обеспечение «Гарант». URL: https://base.garant.ru/11900785/ (дата обращения: 21.08.2020). 
2. СТП-03-153-2001. Методика лабораторная по определению растворяющей и удаляющей способности растворителей АСПО. Уфа: Башнефть, 2001. 9 с.

3. Васильева Т.В., Муфтахова Э.Д. Растворители асфальтосмолопарафиновых отложений на основе газового конденсата // Актуальные проблемы и тенденции развития техносферной безопасности в нефтегазовой отрасли: матер. II науч.-практ. конф. Уфа: Изд-во УГНТУ, 2019. C. $163-164$.

4. Муфтахова Э.Д. Влияние асфальтосмолопарафиновых отложений на аварийность магистральных трубопроводов // Актуальные проблемы и тенденции развития техносферной безопасности в нефтегазовой отрасли: матер. I науч.-практ. конф. Уфа: Изд-во УГНТУ, 2018. С. 311-314.

5. Муфтахова Э.Д., Васильева Т.В., Хафизов И.Ф., Хафизов Ф.Ш., Султанов Р.М. Изучение влияния ультразвуковых колебаний на химический растворитель для удаления асфальтосмолопарафиновых отложений // Техносферная безопасность. 2019. № 2 (23). С. 42-48.

6. Каменщиков Ф.А. Удаление асфальтосмолопарафиновых отложений растворителями. М.-Ижевск: НИЦ «Регулярная и хаотическая динамика», 2008. 384 c.

\section{References}

1. Federal'nyi zakon ot 21.07.1997 № 116-FZ «O promyshlennoi bezopasnosti opasnykh proizvodstvennykh ob"ektov» (s posl. izm. i dop. ot 29.07.2018 g.) [RF Federal Law of July 21, 1997 No. 116-FZ «On Industrial Safety of Hazardous Production Facilities» (with the Additions and Amendments of July 29, 2018)]. Informatsionno-pravovoe obespechenie «Garant». Available at: https://base.garant.ru/11900785/ (accessed 21.08.2020). [in Russian]. 
2. STP-03-153-2001. Metodika laboratornaya po opredeleniyu rastvoryayushchei i udalyayushchei sposobnosti rastvoritelei ASPO [STP-03153-2001. Laboratory Technique for Determining the Dissolving and Removing Ability of ARPD Solvents]. Ufa, Bashneft' Publ., 2001. 9 p. [in Russian].

3. Vasileva T.V., Muftakhova E.D. Rastvoriteli asfal'tosmoloparafinovykh otlozhenii na osnove gazovogo kondensata [Solvents for Asphalt-Resin-Paraffin Deposits Based on Gas Condensate]. Materialy II nauchno-prakticheskoi konferentsii «Aktual'nye problemy i tendentsii razvitiya tekhnosfernoi bezopasnosti v neftegazovoi otrasli» [Materials of the II Scientific-Practical Conference «Actual Problems and Trends in the Development of Technospheric Safety in the Oil and Gas Industry»]. Ufa, UGNTU Publ., 2019, pp. 163-164. [in Russian].

4. Muftakhova E.D. Vliyanie asfal'tosmoloparafinovykh otlozhenii na avariinost' magistral'nykh truboprovodov [Influence of Asphalt-Resin-Paraffin Deposits on the Accident Rate of Main Pipelines] Materialy I nauchnoprakticheskoi konferentsii «Aktual'nye problemy i tendentsii razvitiya tekhnosfernoi bezopasnosti v neftegazovoi otrasli» [Materials of the I ScientificPractical Conference «Actual Problems and Trends in the Development of Technospheric Safety in the Oil and Gas Industry»]. Ufa, UGNTU Publ., 2018, pp. 311-314. [in Russian].

5. Muftakhova E.D., Vasileva T.V., Khafizov I.F., Khafizov F.Sh., Sultanov R.M. Izuchenie vliyaniya ul'trazvukovykh kolebanii na khimicheskii rastvoritel' dlya udaleniya asfal'tosmoloparafinovykh otlozhenii [Studying the Effect of Ultrasonic Vibrations on a Chemical Solvent to Remove Asphalt-ResinParaffin Deposits]. Tekhnosfernaya bezopasnost' - Technosphere Safety, 2019, No. 2 (23), pp. 42-48. [in Russian].

6. Kamenshchikov F.A. Udalenie asfal'tosmoloparafinovykh otlozhenii rastvoritelyami [Removal of Asphalt-Resin-Paraffin Deposits with Solvents]. Moscow-Izhevsk, NITs «Regulyarnaya i khaoticheskaya dinamika» Publ., 2008. 384 p. [in Russian]. 


\section{Сведения об авторах}

\section{About the authors}

Муфтахова Эльмира Дамировна, аспирант кафедры «Пожарная и промышленная безопасность», УГНТУ, г. Уфа, Российская Федерация

Elmira D. Muftakhova, Post-graduate Student of Fire and Industrial Safety Department, USPTU, Ufa, Russian Federation

e-mail: il.elmira@mail.ru

Васильева Татьяна Викторовна, аспирант кафедры «Пожарная и промышленная безопасность», УГНТУ, г. Уфа, Российская Федерация

Tatyana V. Vasilyeva, Post-graduate Student of Fire and Industrial Safety Department, USPTU, Ufa, Russian Federation

e-mail: tatulik_vasileva@mail.ru

Баулин Олег Александрович, канд. техн. наук, ректор, УГНТУ, г. Уфа, Российская Федерация

Oleg A. Baulin, Candidate of Engineering Sciences, Rector, USPTU, Ufa, Russian Federation

e-mail: rector@rusoil.net

Хафизов Ильдар Фанилевич, д-р техн. наук, профессор кафедры «Пожарная и промышленная безопасность», УГНТУ, г. Уфа, Российская Федерация

Ildar F. Khafizov, Doctor of Engineering Sciences, Professor of Fire and Industrial Safety Department, USPTU, Ufa, Russian Federation

e-mail: ildar.hafizov@mail.ru 
Хафизов Фаниль Шамильевич, д-р техн. наук, профессор, заведующий кафедрой «Пожарная и промышленная безопасность», УГНТУ, г. Уфа, Российская Федерация

Fanil Sh. Khafizov, Doctor of Engineering Sciences, Professor, Head of Fire and Industrial Safety Department, USPTU, Ufa, Russian Federation

e-mail: pkpb@mail.ru 